\title{
Epithelial-to-mesenchymal transition and its association with PD-L1 and CD8 in thyroid cancer
}

\author{
Marra Jai Aghajani ${ }^{1,2}$, Tao Yang 2,3,4, Ulf Schmitz ${ }^{5,6,7}$, Alexander James ${ }^{1}$, Charles Eugenio McCafferty ${ }^{1,2}$, \\ Paul de Souza ${ }^{1,2,8}$, Navin Niles ${ }^{1,2,9,10}$ and Tara L Roberts ${ }^{1,2,11}$ \\ ${ }^{1}$ Ingham Institute for Applied Medical Research, Liverpool, New South Wales, Australia \\ ${ }^{2}$ School of Medicine, Western Sydney University, Campbelltown, New South Wales, Australia \\ ${ }^{3}$ Saint Vincent's Clinical School, UNSW Sydney, Sydney, Australia \\ ${ }^{4}$ SydPath, Saint Vincent's Hospital, Sydney, Australia \\ ${ }^{5}$ Computational BioMedicine Laboratory Centenary Institute, The University of Sydney, Camperdown, New South Wales, Australia \\ ${ }^{6}$ Gene \& Stem Cell Therapy Program Centenary Institute, The University of Sydney, Camperdown, New South Wales, Australia \\ ${ }^{7}$ Faculty of Medicine \& Health, The University of Sydney, Camperdown, New South Wales, Australia \\ ${ }^{8}$ School of Medicine, University of Wollongong, New South Wales, Australia \\ ${ }^{9}$ Department of Head \& Neck Surgery, Liverpool Hospital, Liverpool, New South Wales, Australia \\ ${ }^{10}$ Department of Clinical Medicine, Faculty of Medicine and Health Sciences, Macquarie University, Sydney, Australia \\ ${ }^{11}$ South West Sydney Clinical School, UNSW Sydney, Sydney, Australia
}

Correspondence should be addressed to M J Aghajani: marra.aghajani1@gmail.com

\begin{abstract}
Programmed cell death-ligand 1 (PD-L1) has recently been shown to play a role in the regulation of epithelial-to-mesenchymal transition (EMT); however, the relationship between PD-L1 expression, EMT and the inflammatory tumour microenvironment has yet to be investigated in thyroid cancer. To address this issue, we examined the expression of CD8, PD-L1 and the EMT markers E-cadherin and vimentin in a cohort of 74 papillary thyroid cancer (PTC) patients and investigated the association of these with clinicopathologic characteristics and disease-free survival (DFS). The relationship between PD-L1 and EMT was further examined in three thyroid cancer cell lines via Western blot and live cell Key Words

- thyroid cancer

- epithelial-to-mesenchymal transition

- programmed cell death-ligand 1

- CD8

- survival imaging. In order to expand our in vitro findings, the normalised gene expression profiles of 516 thyroid cancer patients were retrieved and analysed from The Cancer Genome Atlas (TCGA). PD-L1 positivity was significantly higher in PTC patients exhibiting a mesenchymal phenotype $(P=0.012)$. Kaplan-Meier analysis revealed that PD-L1 $(P=0.045), \mathrm{CD} 8(P=0.038)$ and EMT status $(P=0.038)$ were all significant predictors for DFS. Sub-analysis confirmed that the poorest DFS was evident in PD-L1 positive patients with EMT features and negative CD8 expression $(P<0.0001)$. IFN- $\gamma$ treatment induced upregulation of PD-L1 and significantly promoted an EMT phenotype in two thyroid cancer cell lines. Our findings suggest that PD-L1 signalling may play a role in stimulating EMT in thyroid cancer. EMT, CD8 and PD-L1 expression may serve as valuable predictive biomarkers in patients with PTC.

\section{Introduction}

The incidence rate of thyroid cancer has risen rapidly over the last 4 decades (1). Differentiated thyroid cancers (DTCs), derived from thyroid follicular cells, are the most common subtype, accounting for over $90 \%$ of all newly diagnosed cases (2). The mounting incidence rate has been attributed to improvements in access to health care systems, increased incidental detection on imaging, more widespread diagnostic testing of asymptomatic thyroid https://ec.bioscientifica.com

https://doi.org/10.1530/EC-20-0268

(c) 2020 The authors Published by Bioscientifica Ltd

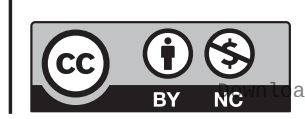

This work is licensed under a Creative Commons Attribution-NonCommercial 4.0 International License. ded from Bioscientifica.com at 04/26/2023 11:49:32AM 
nodules, a rise in the volume and extent of surgery, and modifications in pathology practices (3). However, recent evidence supports a true increase in the occurrence of the disease, possibly due to hormonal, environmental, and genetic factors (4).

Whilst the majority of patients with DTC have a favourable prognosis, 1-9\% present with distant metastasis at the time of initial diagnosis (5), and 7-23\% show distant metastasis during follow-up (6). Moreover, $25-50 \%$ of patients with locally advanced or metastatic DTC become refractory to radioactive iodine (RAI) therapy (7). Inoperable or RAI-refractory metastatic DTC is associated with a 10-year survival of only $10 \%$, and restricted treatment options are currently available (7).

Following initial surgery, the american joint committee on cancer (AJCC)/international union against cancer (UICC) tumour node metastasis (TNM) staging system is commonly implemented to predict disease-specific mortality and is consulted when tailoring decisions concerning postoperative adjunctive therapy. Whilst the AJCC/UICC TNM staging provides important information regarding mortality, it inaccurately predicts the risk of persistent or recurrent disease following initial therapy (8). Research is needed to establish whether the inclusion of additional variables can enhance the predictive capabilities of the current AJCC/UICC TNM staging system.

Programmed cell death protein 1 (PD-1), an inhibitory costimulatory molecule expressed on activated $\mathrm{T}, \mathrm{B}$, and NK cells, plays a critical role in the regulation of peripheral tolerance (9). Two PD-1 binding ligands have been identified; programmed death ligand 1 (PD-L1) and programmed death ligand 2 (PD-L2) (9). PD-L1 is expressed by various human tumours and, following binding to PD-1, has been shown to induce potent inhibition of T-cell mediated anti-tumoural immunity (10). Elevated PD-L1 levels have been associated with a poor prognosis in multiple cancer types (11). We have completed a meta-analysis confirming that non-medullary thyroid cancer patients expressing PD-L1 were three times more likely to have a poorer disease-free survival (DFS) than patients who did not have positive PD-L1 expression (12). Immunotherapies targeting the PD-1/PD-L1 pathway have demonstrated durable responses in selected patients across multiple cancer types, including thyroid cancer (13, 14). However, optimal biomarkers predictive of patient response are currently lacking (15).

Epithelial-to-mesenchymal transition (EMT) is a biological process which plays a central role in cancer progression, metastasis, and drug resistance. During EMT, a polarised epithelial cell, which interacts with the basement membrane, adopts a mesenchymal cell phenotype, which is associated with an enhanced migratory capacity and invasiveness, greater resistance to apoptosis, and markedly increased production of extracellular matrix components (16). Throughout this process, epithelial markers including epithelial cell adhesion molecule (EpCAM) and E-cadherin are downregulated, whilst the mesenchymal markers vimentin and $\mathrm{N}$-cadherin increase in expression. Vimentin has gained much importance as a canonical marker of EMT, with its overexpression associated with accelerated tumour growth, invasion, and poor prognosis (17). E-cadherin is a member of the cadherin family that is primarily detected in epithelial cells. Decreased E-cadherin expression reduces cell-cell contact and promotes EMT induction, resulting in tumour motility (17). Activation of EMT has recently been shown to play a key role in thyroid cancer progression, namely by promoting capsular invasion, extrathyroidal extension and both local and distant metastasis (18). Therefore, E-cadherin and vimentin are promising biomarkers associated with invasiveness, poor differentiation and malignant phenotype.

A bidirectional relationship has recently been established between EMT and PD-L1 expression $(19,20$, $21,22)$. Preliminary observations point to a potential role of EMT markers as predictors of patient response to PD-1/ PD-L1 axis therapies (21). Cancers containing a high level of pre-existing $\mathrm{T}$ cell infiltrate and a pro-inflammatory IFN signature, referred to as 'hot' tumours, have also been shown to more readily respond to PD-1/PD-L1 directed immunotherapies blockade (23). However, the relationship between T cell infiltrate, PD-L1 and EMT status, and their influence on the progression and metastasis of human thyroid cancer, has yet to be investigated. To address this issue, we examined the expression of CD8, PD-L1 and the EMT markers E-cadherin and vimentin in a cohort of PTC patients and investigated the association of these with clinicopathologic characteristics and DFS. The relationship between these markers were further investigated in three thyroid cancer cell lines via Western blot and IncuCyte live cell imaging.

\section{Materials and methods}

\section{Patient characteristics}

Ethics approval was obtained from the south west Sydney Local Health District Human Research Ethics Committee via the Centre for Oncology Education and Research Translation (CONCERT) Biobank, Australia/

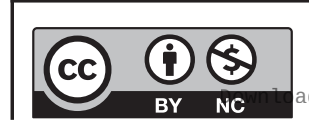


TCRC/3/02-03-2015 (24). In this study, the archived paraffin embedded tissues from 74 PTC patients that underwent surgical resection within the south west Sydney Local Health District from 2006 to 2015 were obtained. Patient demographics and clinicopathologic parameters, including age, sex, tumour stage, tumour size, capsular invasion, extrathyroidal extension, lymphovascular invasion, multicentricity, presence of concurrent lymphocytic thyroiditis and lymph node metastasis, were acquired via retrospective medical record review. Standard American Joint Committee on Cancer, 8th edition, tumour-node-metastases (TNM) scoring was implemented for thyroid cancer staging. All patients were followed up for survival status until October 2019.

DFS was defined as the period between completion of primary treatment and detection of residual disease, recurrent disease or death. This definition was adopted from the 2015 American Thyroid Association (ATA) Management Guidelines (25). An excellent response (absence of persistent tumour) following initial therapy was defined as negative imaging and either a low serum thyroglobulin (Tg) during thyroid stimulating hormone (TSH) suppression $(\mathrm{Tg}<0.2 \mathrm{ng} / \mathrm{mL}$ ) or following stimulation (Tg $<1 \mathrm{ng} / \mathrm{mL})$. A structural incomplete response was defined as structural or functional evidence of disease with any Tg level, whilst a biochemical incomplete response was designated to patients with negative imaging and a suppressed $\mathrm{Tg} \geq 1 \mathrm{ng} / \mathrm{mL}$ or a stimulated $\mathrm{Tg} \geq 10 \mathrm{ng} / \mathrm{mL}$. Patients that did not experience tumour recurrence were censored at the last follow-up contact.

\section{Immunohistochemistry}

Formalin-fixed paraffin-embedded (FFPE) tissues were collected from 74 patients with a confirmed diagnosis of PTC and were used to construct tissue microarrays (TMAs). Considering spatial heterogeneity, duplicate tissue cores of $0.6 \mathrm{~mm}$ diameter were obtained from the normal tissue, tumour centre and tumour periphery. Tissue blocks were cut into $4-\mu \mathrm{m}$ sections for analysis. Sections were stained with anti-PD-L1 (clone SP263) rabbit monoclonal primary antibody (Ventana Medical Systems) on the Ventana BenchMark Ultra automated staining platform using the OptiView Detection Kit. The Leica Bond III Immuno-autostainer was used for CD8 staining with the mouse anti-human CD8 clone C8/144B, 1:100 (DAKO). TMAs were also stained with the monoclonal mouse anti-human e-cadherin clone NCH-38, 1:100 (DAKO) and monoclonal mouse antivimentin clone V9, 1:500 (DAKO).
The scoring of vimentin and E-cadherin was based on previously published methods $(26,27)$. Vimentin staining was scored as follows: $0=$ no expression, $1=$ fragmented membranous and/or weak to moderate expression, $2=$ fragmented strong or fully membranous moderate expression, and $3=$ fully membranous strong expression. A score of $\geq 2$ was considered as positive vimentin expression. The area intensity score method was used to score E-cadherin, which incorporates both the staining intensity and the number of positive cells. The intensity of staining was scored as $0=$ negative, $1=$ weak, $2=$ moderate, and $3=$ intense. The percentage of positively stained cells was scored as follows; $0=0-5 \%$ positive cells, $1=6-25 \%$ positive cells, $2=26-50 \%$ positive cells, $3=51-75 \%$ positive cells, and $4=75-100 \%$ positive cells. The two scores for the intensity and the percentage of positive cells were then multiplied to generate a final score ranging from 0 to 12 . E-cadherin expression was dichotomised as negative (score of 0-6) and positive (score of 7-12) for outcome analyses. Patients considered to be EMT positive were those that were scored both vimentin 'positive' and E-cadherin 'negative'.

PD-L1 expression was scored based on the percentage of immunopositively stained cancer cells, with a score of $\geq 1 \%$ considered positive PD-L1 staining. Scoring of CD8 expression was performed as previously described (28). Briefly, a quantitative score based on the percentage of immunopositively stained cells among total cells was given according to the following scale: 1 ( $<1 \%$ cells); 2 (1-10\% cells); 3 (11-33\% cells); 4 (34-66\% cells) and 5 (67-100\% cells). Staining intensity was then scored as follows: 0 (none), 1+ (mild), 2+ (moderate), and 3+ (intense). Finally, Allred scores (ranging from 1 to 8 ) were calculated by adding the percentage positivity scores and the intensity scores for each of the sections. The median value was used to separate the patient cohort into two groups with either negative or positive CD8 expression. Figure 1 provides representative cases of E-cadherin, vimentin, PD-L1 and CD8 scoring. Two authors (T Y and M A) blinded to tumour clinicopathological characteristics and patient outcomes scored the slides, with any discrepancies resolved by consensus.

\section{Cell culture}

The follicular thyroid cancer (FTC) and PTC cell lines FTC-133 and K1 were cultured in DMEM: Ham's F12 (1:1) medium (Sigma-Aldrich) containing $2 \mathrm{mM}$ glutamine (Thermo Fisher) and 10\% foetal bovine serum (FBS) (Thermo Fisher). The anaplastic thyroid cancer (ATC) cell line 8505C was cultured in EMEM (HBBS) medium supplemented with

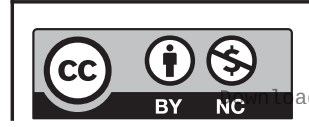

This work is licensed under a Creative Commons Attribution-NonCommercial 4.0 International License. ded from Bioscientifica.com at 04/26/2023 11:49:32AM 
A

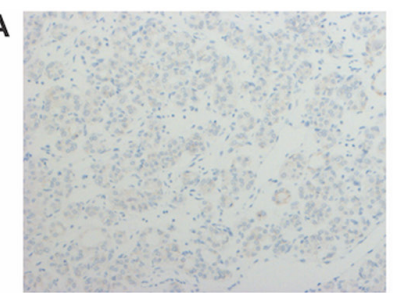

C

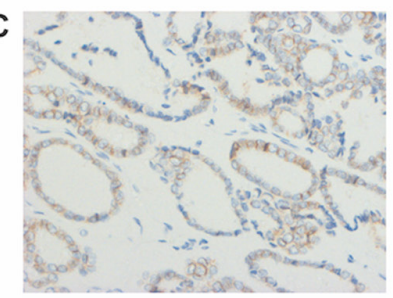

E

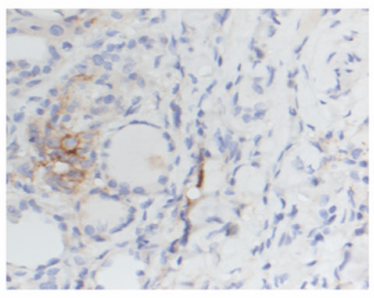

G

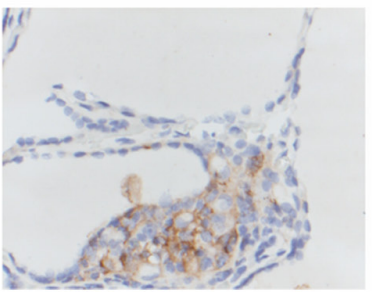

B

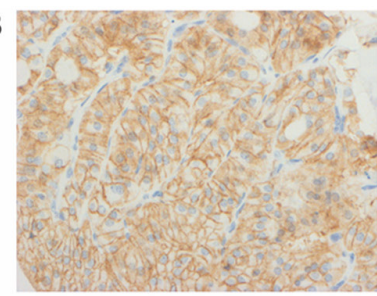

D

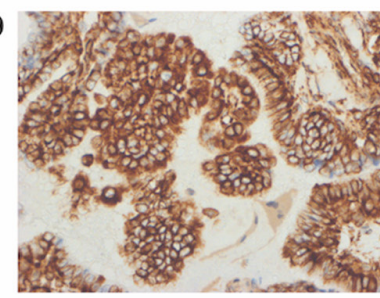

$\mathrm{F}$

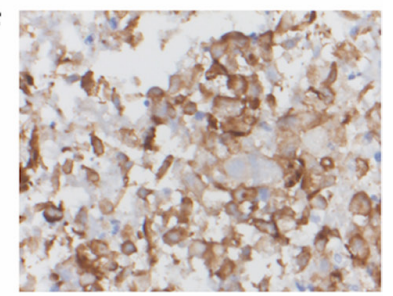

$\mathrm{H}$

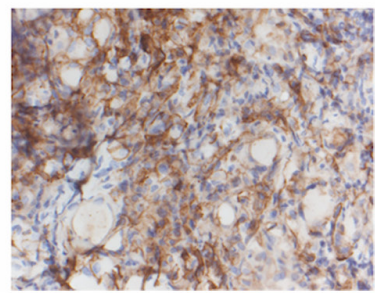

Figure 1

Representative staining of formalin-fixed paraffin-embedded (FFPE) tissues from PTC patients. Negative (A) and positive (B) immunohistochemical (IHC) staining pattern for E-cadherin expression. Negative (C) and positive (D) IHC staining pattern for vimentin expression. Negative $(E)$ and positive $(F) I H C$ staining pattern for PD-L1 expression. Negative $(G)$ and positive $(H) I H C$ staining pattern for $\mathrm{CD}^{+}$expression. Images were taken at $5 \times$ magnification (A) and 40× magnification (remaining images).

$2 \mathrm{mM}$ glutamine (ThermoFisher), 1\% non-essential amino acids (Sigma-Aldrich) and 10\% FBS (Thermo Fisher). All media were supplemented with penicillin-streptomycin (Thermo Fisher) and all cells were incubated at $37^{\circ} \mathrm{C}$ in $5 \%$ $\mathrm{CO}_{2}$. EMT was induced using recombinant human IFN- $\gamma$ (300-02) (10 ng/mL, Peprotech).

Live cell imaging assays were performed using the IncuCyte ${ }^{\circledR}$ Live-Cell Analysis System (Essen BioScience, Ann Arbor, MI, USA). Cells were imaged at $10 \times$ magnification at $37^{\circ} \mathrm{C}$ with $5 \% \mathrm{CO}_{2}$. Images were acquired every $4 \mathrm{~h}$ for $48 \mathrm{~h}$.

\section{Western blot analysis}

Western blotting was performed as described previously (29). Briefly, cells were harvested and lysed in RIPA buffer

supplemented with phosphatase (sodium fluoride, sodium molybdite, sodium pyrophosphate) and complete Mini, EDTA-free protease inhibitors (Roche). 15-25 $\mu \mathrm{g}$ total protein (depending on different proteins) were separated by SDS-PAGE and then transferred to polyvinylidene difluoride membranes (Roche). For each gel, the same amount of protein was loaded per lane. Membranes were then blocked in 5\% non-fat milk in Tris-buffered salineTween for $1 \mathrm{~h}$. The immunoblotting was performed by incubation at $4^{\circ} \mathrm{C}$ overnight with the following primary antibodies: anti-PD-L1 antibody (13684) (Cell Signaling Technology), anti-E-cadherin (ab15148) (Abcam), antivimentin (ab92547) (Abcam) and $\beta$-actin (Cell Signaling Technology), which was used as an endogenous protein for normalisation. Blots were then washed and incubated with a 1:1000 dilution of anti-Rabbit IgG H\&L (HRP)conjugated secondary (Cell Signaling Technology) or a 1:1000 dilution of anti-mouse IgG H\&L (HRP)-conjugated secondary (Cell Signaling Technology). Signals were detected by enhanced chemiluminescence Plus reagents (PerkinElmer) and images were captured using a Licor Odyssey System. Signal quantification was obtained using Image Studio Lite software (Version 5.2.5). All experiments were performed in triplicate.

\section{Dataset analysis}

Normalised gene expression profiles (RNA Seq V2 RSEM) of 516 PTC patients were retrieved from The Cancer Genome Atlas (TCGA) via the Cancer Genomics Data Server package (cgdsrv1.2.10; github.com/cBioPortal/cgdsr). The EMT score was computed using the mean expression of mesenchymal genes (ZEB1, ZEB2, SNAI1, SNAI2, TWIST1, TWIST2, VIM, FOXC2, SOX10, FN1, MMP2, MMP3) minus the mean expression of epithelial genes (CDH1, CLDN3, CLDN4, CLDN7, DSP), as previously described by Alsuliman et al. (22). The IFN gene signature was based on the 18-gene tumour inflammation signature reported by Ayers et al. (30), which included the following genes; PSMB10, HLA-DQA1, HLA-DRB1, CMKLR1, HLA-E, NKG7, CD8A, CCL5, CXCL9, CD27, CXCR6, IDO1, STAT1, TIGIT, LAG3, CD274, PDCD1LG2, CD276. Correlation coefficients of PD-L1 expression and EMT score, or mean expression of the IFN signature genes and EMT score were computed using Pearson correlation. Survival analyses (Kaplan-Meier) based on DFS were performed using the survival package (v2.44 1.1; github.com/therneau/ survival). The heatmap was generated using the Complex Heatmap package (v2.1.0) (31). All data analyses have been performed using $\mathrm{R}$ version 3.6.0. 


\section{Statistical analysis}

Correlations were analysed using the Pearson's chisquared test and Fisher's exact test. The student $t$-test with Welch's correction was implemented to compare differences between control and treated cell lines. Two-sided $P$ values $<0.05$ was considered statistically significant. Results are representative of three independent experiments and are expressed as mean \pm s.D. Survival curves were plotted using the Kaplan-Meier method and compared using the log-rank test. A Cox regression model was used to perform multivariate analyses. All statistical analyses were completed using GraphPad Prism v.7.0d and SPSS software (version 22).

\section{Results}

\section{Patient characteristics}

The main characteristics of the 74 PTC patients included in the study are detailed in Table 1 . The median age of the patients at diagnosis was 51 years. The majority of patients were female $(65 / 74)$ or had a tumour size less than $2 \mathrm{~cm}$ (59/74). Only 10 patients in the cohort were diagnosed with TNM stage III/IV disease. This was expected as the majority of thyroid cancers are identified and diagnosed at an early stage.

\section{PD-L1 expression is associated with EMT status in papillary thyroid cancer patients}

The expression of E-cadherin, vimentin, PD-L1 and CD8were all assessed via IHC staining of TMAs. Of the 74 cases, 16 were scored positive for E-cadherin whilst 51 patients expressed positive vimentin staining. Forty-five cases were considered EMT positive (E-cadherin negative and vimentin positive). Positive PD-L1 expression was observed in 49 patients. PD-L1 positivity was significantly higher in PTC patients displaying a mesenchymal phenotype (Fig. 2; $P=0.012$ ), as determined by negative E-cadherin and positive vimentin expression. Elevated CD8 levels were identified in 39 patients.

\section{PD-L1, EMT and CD8 are predictive for DFS in PTC patients}

EMT status and the expression of PD-L1, E-cadherin, vimentin, and the presence of CD8T cells were not significantly associated with any clinicopathological characteristics (Supplementary Tables 1, 2, 3, 4 and 5,
Table 1 Clinical summary of patients.

\begin{tabular}{lc}
\hline Patient characteristics & Number of patients $(n=74)$ \\
\cline { 1 - 2 } Age & \\
Median (range) & $(24-80)$ \\
$<55$ & 44 \\
$\geq 55$ & 30 \\
Sex & \\
$\quad$ Male & 9 \\
Female & 65 \\
TNM stage & \\
I/II & 64 \\
III/IV & 10 \\
Tumour size & \\
$\quad<2$ cm & 59 \\
$\quad \geq 2$ cm & 15 \\
Multifocality & \\
Present & 14 \\
Absent & 60 \\
Extrathyroidal extension & \\
Present & 15 \\
Absent & 59 \\
Lymphovascular invasion & \\
Present & 68 \\
Absent & \\
Lymph node metastases & \\
Present & \\
Absent & \\
Concurrent Hashimoto's thyroiditis & \\
Present & \\
Absent & \\
\hline
\end{tabular}

see section on supplementary materials given at the end of this article). Interestingly, all six PTC patients which experienced lymphovascular invasion were EMT positive (i.e. displayed a mesenchymal phenotype); however, this did not reach statistical significance (Table 2; $P=0.075$ ), likely due to the small number of patients in this sub-group.

At the time of analysis, the median duration of follow-up of the 74 cases was 45.5 months (range:

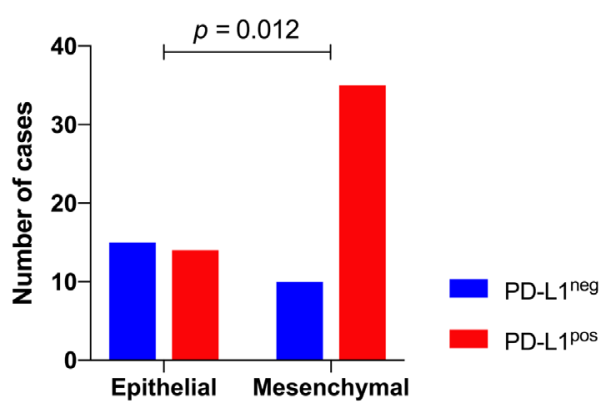

Figure 2

PD-L1 expression is associated with mesenchymal phenotype. Cases were separated in PD-L1 negative (blue) $(n=25)$ and positive (red) $(n=49)$ subgroups. These were then assessed for epithelial vs mesenchymal state. By Fisher's exact test there was a significant positive association between PD-L1 expression and a mesenchymal phenotype. 
Table 2 Univariate and multivariate analysis of clinicopathologic factors associated with DFS in PTC cases.

\begin{tabular}{|c|c|c|c|c|}
\hline \multirow[b]{2}{*}{ Patient characteristics } & \multirow{2}{*}{$\begin{array}{c}\text { Univariate analysis } \\
P \text { value } \\
\end{array}$} & \multicolumn{3}{|c|}{ Multivariate analysis } \\
\hline & & $\mathrm{HR}$ & $95 \% \mathrm{Cl}$ & $P$ value \\
\hline \multicolumn{5}{|l|}{ Age } \\
\hline \multicolumn{5}{|l|}{$<55$ vs } \\
\hline$\geq 55$ & 0.736 & 1.986 & $0.546-7.226$ & 0.298 \\
\hline \multicolumn{5}{|l|}{ Sex } \\
\hline \multicolumn{5}{|l|}{ Male vs } \\
\hline Female & 0.362 & 1.258 & $0.281-5.643$ & 0.764 \\
\hline \multicolumn{5}{|l|}{ TNM stage } \\
\hline \multicolumn{5}{|l|}{ | vs || vs } \\
\hline III vs IV & 0.061 & 1.043 & $0.488-2.231$ & 0.913 \\
\hline \multicolumn{5}{|l|}{ Tumour size } \\
\hline \multicolumn{5}{|l|}{$<2 \mathrm{~cm}$ vs } \\
\hline$\geq 2 \mathrm{~cm}$ & 0.327 & 0.956 & $0.253-3.608$ & 0.947 \\
\hline \multicolumn{5}{|l|}{ Multifocality } \\
\hline \multicolumn{5}{|l|}{ Present vs } \\
\hline Absent & 0.128 & 2.340 & 0.604-9.063 & 0.219 \\
\hline \multicolumn{5}{|l|}{ Extrathyroidal extension } \\
\hline \multicolumn{5}{|c|}{ Present vs } \\
\hline Absent & 0.154 & 1.050 & $0.260-4.241$ & 0.945 \\
\hline \multicolumn{5}{|c|}{ Lymphovascular invasion } \\
\hline \multicolumn{5}{|c|}{ Present vs } \\
\hline Absent & $0.004 *$ & 2.826 & $0.416-19.188$ & 0.288 \\
\hline \multicolumn{5}{|l|}{ Lymph node metastases } \\
\hline \multicolumn{5}{|l|}{ Present vs } \\
\hline Absent & $0.006 *$ & 1.819 & $0.441-7.515$ & 0.408 \\
\hline \multicolumn{5}{|c|}{ Concurrent Hashimoto's thyroiditis } \\
\hline \multicolumn{5}{|l|}{ Present vs } \\
\hline Absent & 0.424 & 0.900 & $0.242-3.346$ & 0.875 \\
\hline \multicolumn{5}{|l|}{ PD-L1 } \\
\hline \multicolumn{5}{|l|}{ Negative vs } \\
\hline Positive & $0.048 *$ & 3.053 & $0.599-15.552$ & 0.179 \\
\hline \multicolumn{5}{|l|}{$\mathrm{CD} 8$} \\
\hline \multicolumn{5}{|l|}{ Negative vs } \\
\hline Positive & $0.028 *$ & 0.536 & $0.135-2.130$ & 0.376 \\
\hline \multicolumn{5}{|l|}{ EMT status } \\
\hline \multicolumn{5}{|l|}{ E-cadneg/Vim neg vs } \\
\hline E-cadneg/Vim pos vs & & & & \\
\hline E-cadpos $/$ Vim $^{\text {neg }}$ vs & & & & \\
\hline E-cadpos/Vimpos & $0.026 *$ & 3.132 & $1.102-8.897$ & $0.032 *$ \\
\hline
\end{tabular}

2-129 months). A total of 16 cases experienced tumour persistence and/or recurrence. Univariate analysis revealed that e-cadherin was not a significant predictor of DFS in our cohort (Fig. 3A; $P=0.384$ ); however, a positive vimentin score was significantly associated with a reduced DFS (Fig. 3B; $P=0.003$ ). A high density of tumoural CD8T cells was a favourable biomarker predictive of improved DFS (Table 2, Fig. 3C; $P=0.028$ ), whilst positive PD-L1 expression was significantly associated with an increased incidence of persistent or recurrent disease (Table 2, Fig. $3 \mathrm{D} ; P=0.048$. The presence of lymph node metastases (Table 2; $P=0.006$ ) and lymphovascular invasion $(P=0.004)$ were also significant predictors of DFS on univariate analysis in our cohort.

\section{Subgroup analysis}

Based on EMT marker staining, we categorised all 74 tissue sections into four subgroups; (i) E-cadherin ${ }^{\text {negative/ }}$ vimentin $^{\text {negative }}(n=13)$, (ii) E-cadherin ${ }^{\text {negative }} /$ vimentin $^{\text {positive }}$ ( $n=45)$, (iii) E-cadherin ${ }^{\text {positive }} /$ vimentin $^{\text {negative }}(n=10)$, and (iv) E-cadherin ${ }^{\text {positive/vimentin }}{ }^{\text {positive }}(n=6)$. Patients that were E-cadherin $^{\text {negative }} /$ vimentin $^{\text {positive }}$ and E-cadherin ${ }^{\text {positive / }}$ vimentin $^{\text {positive }}$ experienced the shortest DFS compared to the other two subgroups (Fig. 4A; $P=0.026$ ). The patients were then allocated one of two major subgroups; (i) an EMT positive subgroup $(n=45)$, including patients with a negative E-cadherin and positive vimentin scores, or (ii) an EMT negative subgroup $(n=29)$, which included 

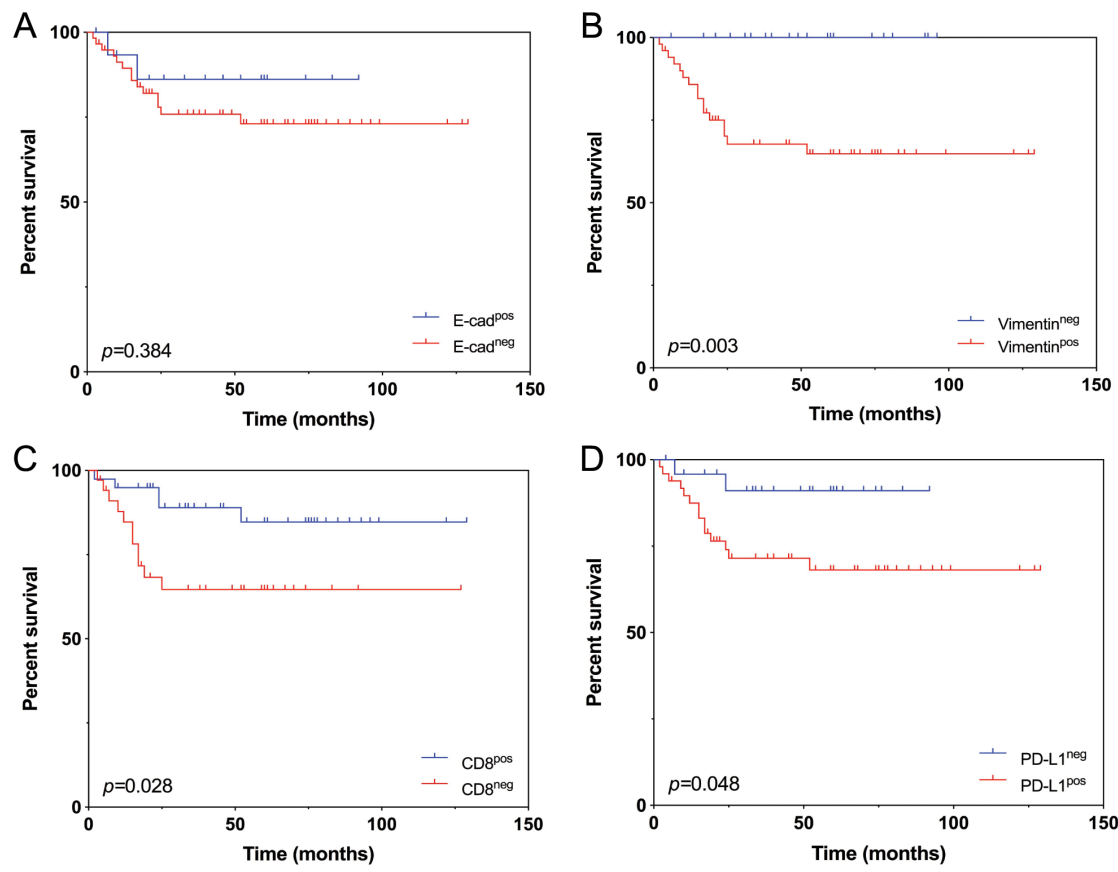

\begin{abstract}
Figure 3
Vimentin, CD8 ${ }^{+}$and PD-L1 were all predictive for DFS in the PTC cohort. Kaplan-Meier curves for DFS of PTC patients with positive and negative E-cadherin expression (E-cad ${ }^{\text {pos }}(n=16)$ vs E-cad ${ }^{\text {neg }}$ $(n=58) ; P=0.384)(\mathrm{A})$, vimentin expression (Vimentin $^{\text {pos }}(n=51)$ vs Vimentin ${ }^{\text {neg }}(n=23)$; $P=0.003$ ) (B), CD8 ${ }^{+}$density (CD8pos $(n=39)$ vs. $\left.\mathrm{CD}^{\text {neg }}(n=35) ; P=0.028\right)(\mathrm{C})$ and positive or negative PD-L1 expression (PD-L1 pos $(n=49)$ vs. PD-L1 $\left.{ }^{\text {neg }}(n=25) ; P=0.048\right)(D) . P$-values were calculated by the log-rank test.
\end{abstract}

all other patients. EMT positive cases had a significantly higher incidence of recurrence compared to EMT negative patients $(P=0.021)$. On multivariate analyses, EMT status remained as the only significant independent predictor for DFS (Table 2; $P=0.032$ ).

Further sub-analysis was performed to assess the relationship between PD-L1, EMT and CD8 expression, and prognosis. Patients that were scored both EMT and PD-L1 negative $(n=39)$ had the longest DFS compared with all other patients $(n=34)$ (Fig. $4 \mathrm{~B} ; P=0.003)$. Moreover, PD-L1 $1^{\text {negative }} / \mathrm{EMT}^{\text {negative }} / \mathrm{CD} 8^{\text {positive }}$ patients ( $n=7$ ) experienced no recurrent or persistent disease, whilst those considered PD-L1 ${ }^{\text {positive }} / \mathrm{EMT}^{\text {positive }} / \mathrm{CD} 8^{\text {negative }}$ $(n=15)$ experienced the shortest DFS (Fig. 4C; $P<0.0001)$.
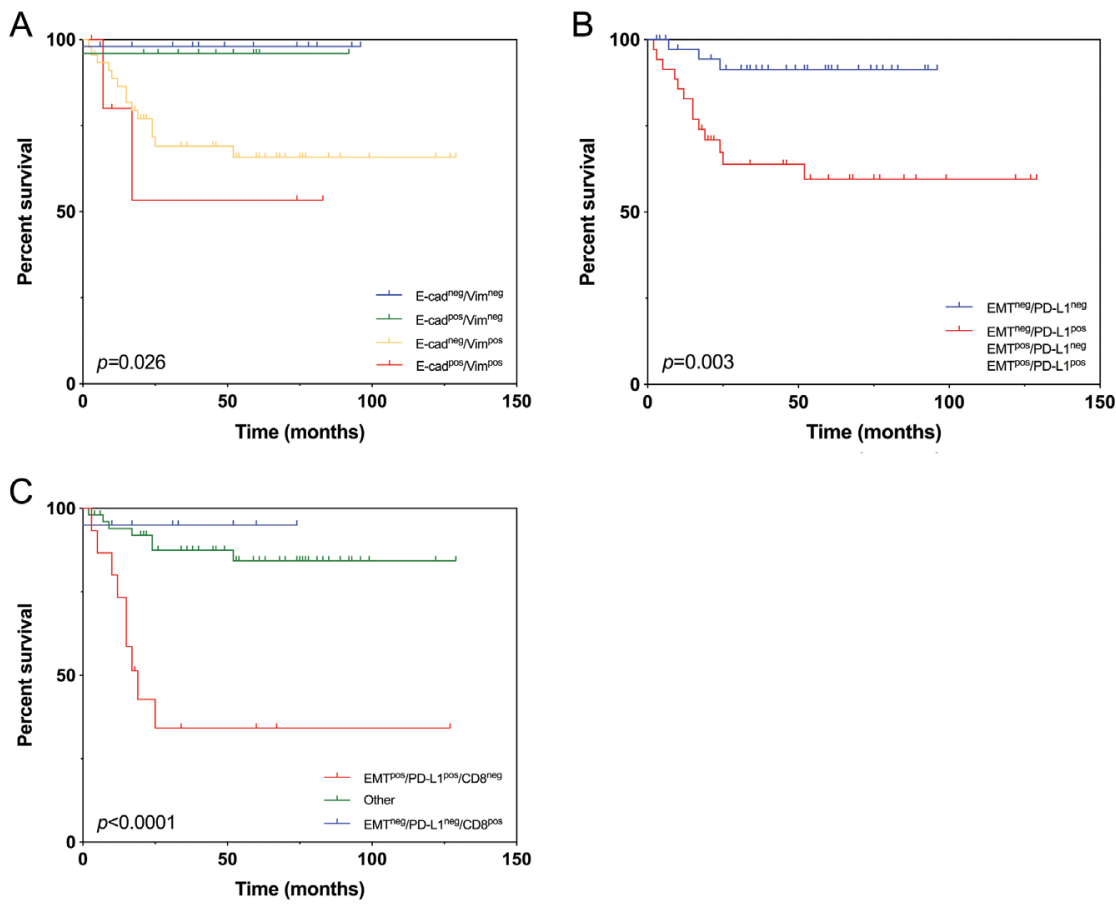

https://ec.bioscientifica.com https://doi.org/10.1530/EC-20-0268

(c) 2020 The authors Published by Bioscientifica Ltd

\section{Figure 4}

Patients positive for EMT and PD-L1 expression, and negative for $C D 8^{+} \mathrm{T}$-cell expression experienced the worst DFS on subgroup analysis. Kaplan-Meier curves for DFS of PTC patients with positive and negative E-cadherin and Vimentin expression (E-cad ${ }^{\text {neg }} / \mathrm{Vim}^{\text {neg }}(n=13)$ vs E-cadpos $/ \operatorname{Vim}^{\text {neg }}(n=10)$ vs E-cad ${ }^{\text {neg }} / \operatorname{Vim}^{\text {pos }}(n=45)$ vs E-cadpos/Vimpos $(n=6) ; P=0.026)(A)$, positive and negative EMT status and PD-L1 expression (EMT $^{\text {neg/PD-L }} 1^{\text {neg }}(n=39)$ vs EMT ${ }^{\text {neg/PD-L }} 1^{\text {pos }}$ and $\mathrm{EMT}^{\text {pos }} / \mathrm{PD}-\mathrm{L}^{\text {neg }}$ and EMT ${ }^{\text {pos }} / \mathrm{PD}-\mathrm{L} 1^{\text {pos }}(n=35)$; $P=0.003)(B)$, and positive and negative EMT status, PD-L1 expression and CD8 density (EMT ${ }^{\text {pos }} /$ PD-L $1^{\text {pos }} / C D 8^{\text {neg }}(n=15)$ vs $\mathrm{EMT}^{\text {neg/PD-L }} 1^{\text {neg }} / \mathrm{CD}^{\text {pos }}(n=7)$ vs Other $(n=52)$; $P<0.0001)$ (C). $P$ values were calculated by the log-rank test. 


\section{Clinical datasets and mRNA expression profiles}

In order to expand our IHC findings, the normalised gene expression profiles of 516 thyroid cancer patients were retrieved from TCGA. The profiles were comprised of 399 PTCs, 107 FTCs, 1 patient with PDTC, 1 patient with well-differentiated thyroid cancer, and 8 thyroid cancers that were not otherwise specified. An EMT score of each thyroid cancer sample was calculated using the mean expression of mesenchymal genes minus the mean expression of epithelial genes (additional detail in the 'Materials and methods' section). This was then correlated with PD-L1 gene expression, or the mean expression of IFN signature genes (Fig. 5F). We observed a moderate positive linear relationship between EMT status and PD-L1 expression (Fig. 5A; $r=0.481171$ ) and an IFN gene signature (Fig. 5B; $\mathrm{r}=0.360384$ ). When considering only PTCs $(n=399)$, the correlation coefficient between EMT status and PD-L1 strengthened (Fig. 5C; $r=0.502354$ ). Moreover, in the subset of PTCs which experienced disease recurrence/progression $(n=40)$, a strong correlation was identified between positive PD-L1 and EMT expression (Fig. 5D; $r=0.623002$ ). This was also observed when patients of all subtypes which experienced disease recurrence/progression $(n=49)$ were included (Fig. 5E; $r=0.656826$ ). These results align with the findings from our patient cohort, in which we observed a significant association between PD-L1 expression and EMT status. In the TCGA PTC patient cohort, a higher EMT and mesenchymal genes score were both significantly associated with poorer DFS outcomes ( $P=0.0027$ (Fig. 5G) and $P=0.0085$ (Fig. 5H), respectively). Similarly, the EMT status remained the only significant predictor for DFS on multivariate analysis in our cohort. Together, these findings confirm a significant association between PD-L1 and EMT status in PTC.
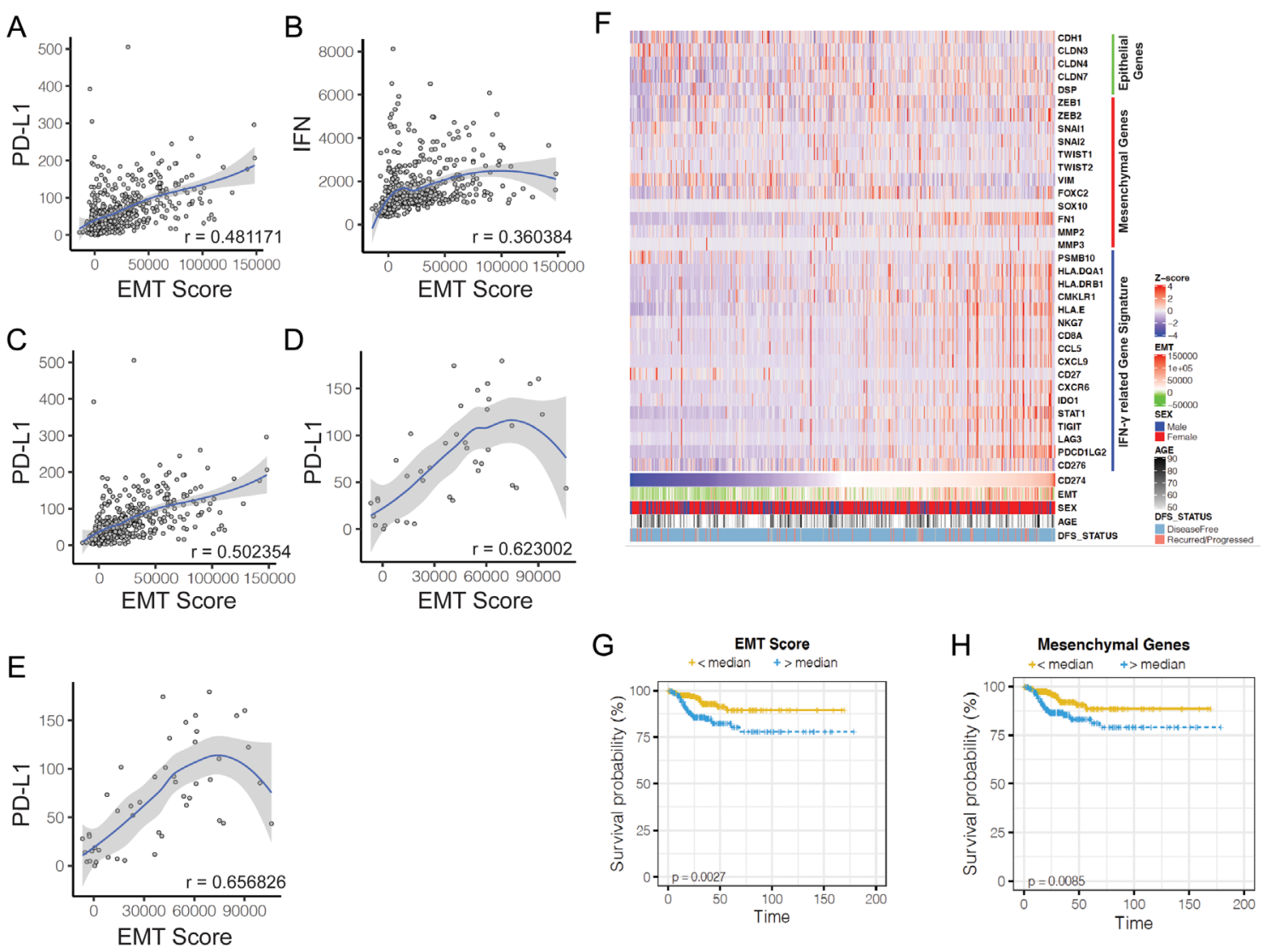

\section{Figure 5}

Correlation of PD-L1 expression, EMT and an IFN gene signature in thyroid cancer using TCGA gene expression dataset. Gene expression dataset from the TCGA thyroid cancer samples (total of 516 patients) showing the correlation between PD-L1 expression with EMT score $(r=0.481171)$ (A), correlation between IFN score and EMT score ( $r=0.360384)$ (B). Correlation between PD-L1 expression and EMT score in PTC patients only $(n=399)(r=0.502354)$ (C). Correlation between PD-L1 expression and EMT score in PTC patients experiencing disease recurrence/progression $(n=40)(r=0.623002)$ (D). Correlation between PD-L1 expression and EMT score in all patients experiencing disease recurrence/progression $(n=49)(r=0.656826)(E)$. Heat map showing mRNA expression level of epithelial genes, mesenchymal genes, and IFN- $\gamma$ related genes (F). Kaplan-Meier curves for DFS of TCGA thyroid cancer patients with positive and negative $\operatorname{EMT} \operatorname{score}(P=0.0027)(\mathrm{G})$ and positive and negative mesenchymal gene expression $(P=0.0085)(\mathrm{H})$.

https://ec.bioscientifica.com https://doi.org/10.1530/EC-20-0268 (c) 2020 The authors Published by Bioscientifica Ltd

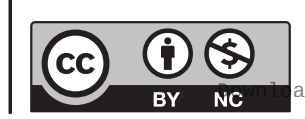

This work is licensed under a Creative Commons Attribution-NonCommercial 4.0 International License. ded from Bioscientifica.com at 04/26/2023 11:49:32Am 


\section{IFN-y induced PD-L1 expression and EMT in vitro}

In order to investigate the relationship between PD-L1 expression and EMT status, PD-L1 expression was induced via IFN- $\gamma$ treatment in three thyroid cancer cell lines (K1; papillary thyroid cancer, FTC-133; follicular thyroid cancer, 8505C; anaplastic thyroid cancer). Following treatment, changes in PD-L1, E-cadherin and vimentin protein expression were assessed via Western blot. Treatment with $10 \mathrm{ng} / \mathrm{mL}$ of IFN- $\gamma$ for $48 \mathrm{~h}$ significantly increased the expression of PD-L1 in all cell lines (Fig. 6A, B and C). Upregulation in PD-L1 occurred alongside a significant decrease in E-cadherin and increase in vimentin expression in two of the thyroid cancer cell lines examined (Fig. 6A and $\mathrm{B})$. In the $8505 \mathrm{C}$ and $\mathrm{K} 1$ cell lines, the morphological appearance changed from cobblestone tightly arranged cells (epithelial like) to spindle -shaped cells that were widely distributed (mesenchymal like) (Fig. 6D and E).
These findings were not observed in the FTC cell line. The FTC-133 cell line, which was originally obtained from a lymph node metastasis of a patient with FTC, demonstrates a spindle-shaped morphology at baseline (Fig. 6F) as well as strong levels of vimentin expression in untreated cells (Fig. 6C). This cell line may therefore possess a more mesenchymal phenotype constitutively and may not be expected to undergo the same morphological changes observed in 8505C and $\mathrm{K} 1$ cells. Collectively, these results suggest that IFN- $\gamma$ treatment promoted PD-L1 expression and induced EMT characteristics in K1 and 8505C cells.

\section{Discussion}

The significant role of the PD-1/PD-L1 pathway in suppressing the anti-tumour immune response has been well established (32). PD-1/PD-L1 pathway proteins are
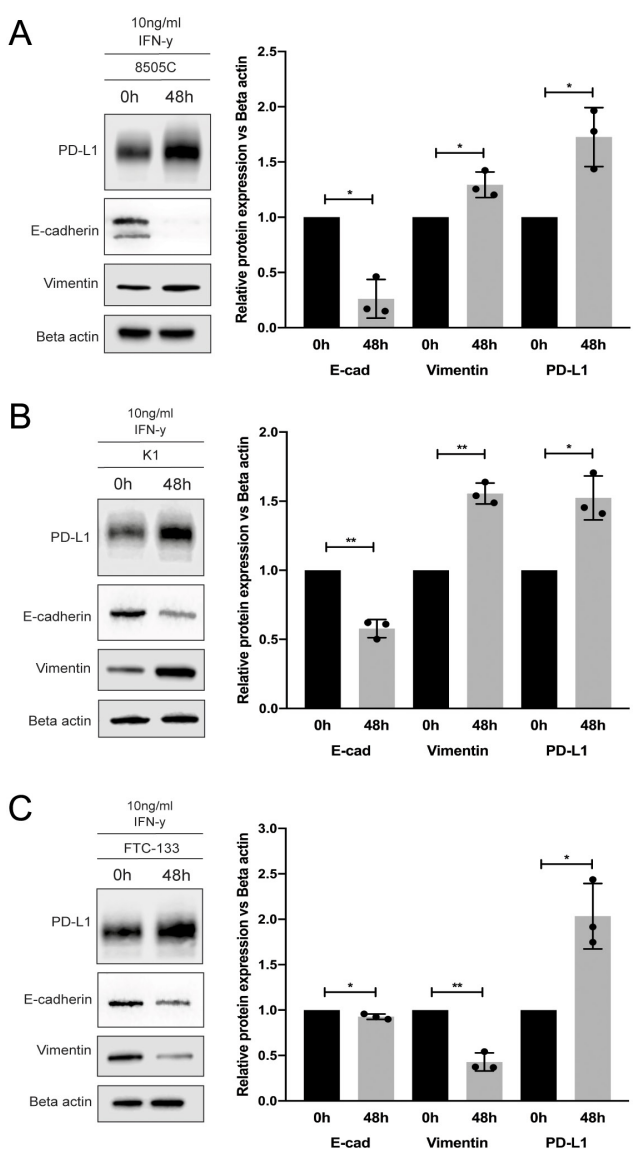
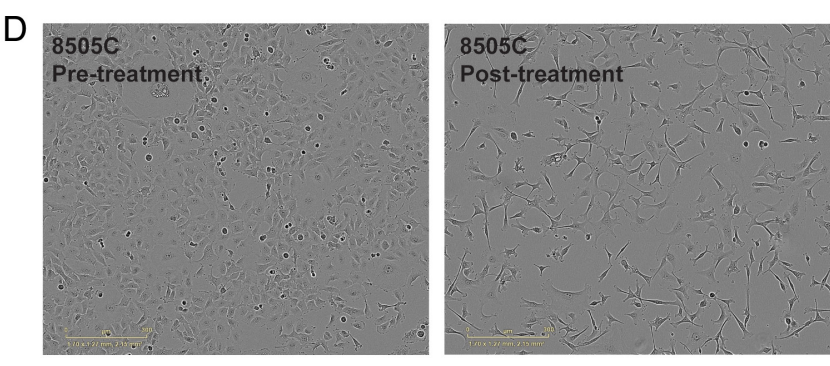

E
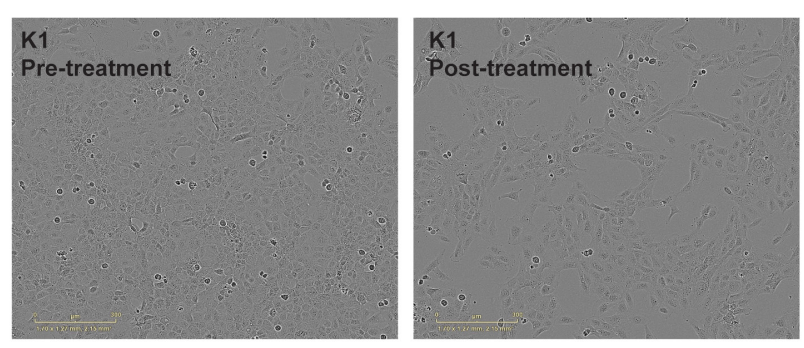

$\mathrm{F}$
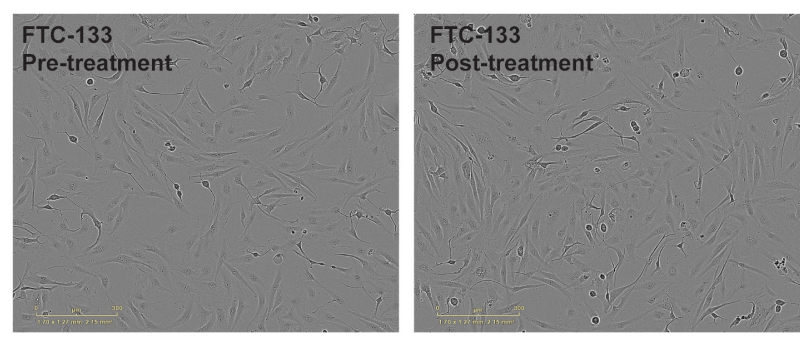

\section{Figure 6}

IFN- $\gamma$ treatment upregulated PD-L1 expression and induced EMT in thyroid cancer cell lines. PD-L1, E-cadherin and vimentin expression following 48-h $10 \mathrm{ng} / \mathrm{mL}$ IFN- $\gamma$ treatment in 8505C (A), K1 (B) and FTC-133 (C) thyroid cancer cells lines. A morphological change indicative of EMT was observed in the $8505 \mathrm{C}$ (D) and K1 (E) cell lines. This was not evident in the FTC (F) cell line which demonstrated a more mesenchymal morphology at baseline. Quantification of Western blotting data $(n=3)$ was performed via Licor Odyssey, which showed a significant reduction in PD-L1 expression in all cell lines assessed. $P$ values were calculated by the student $t$ test with Welch's correction. $* P<0.05, * \star P<0.01$. All experiments were performed in triplicate. The bars in each column show the mean, and the error bars demonstrate the s.D. from three independent experiments. The scatter dot plots represent the individual data points.

https://ec.bioscientifica.com https://doi.org/10.1530/EC-20-0268 (c) 2020 The authors Published by Bioscientifica Ltd

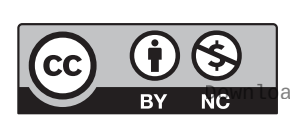

This work is licensed under a Creative Commons Attribution-NonCommercial 4.0 International License. ded from Bioscientifica.com at $04 / 26 / 2023$ 11:49:32AM 
highly expressed in patients with more aggressive thyroid cancer variants. Whilst stage I PTCs exhibited low levels of cytoplasmic PD-L1 staining assessed via IHC, markedly increased expression has been observed in stage III and IV PTC cases (33). A significant increase in membrane PD-L1 expression was correlated with a higher risk of aggressive disease, distant metastasis and death in stage IV patients (33). We have recently published a meta-analysis confirming that elevated PD-L1 status is a prognostic indicator for reduced DFS in patients with non-medullary thyroid carcinoma (12). Patients with upregulated PD-L1 were up to three times as likely to have a poorer prognosis than those with negative PD-L1 expression. These findings suggest that PD-L1 may provide clinicians with a prognostic biomarker capable of identifying thyroid cancer patients with aggressive disease at an earlier stage and may be useful in the selection of individuals that would derive durable clinical benefit from anti-PD-1/ PD-L1 immunotherapy.

Immunotherapies targeting the PD-1/PD-L1 axis have exhibited durable responses and improved survival rates across numerous cancer types (34). However, a large fraction of patients still fail to benefit from treatment, with response rates of less than $20 \%$ often reported (35). The evaluation of PD-L1 expression via IHC is currently the most widely implemented tool used in the selection of patients for treatment with PD-1/PD-L1 directed immunotherapies (36). Several concerns regarding its use have been recognised, including inconsistencies in expression between archival versus fresh biopsy, inter- and intra-tumoural heterogeneity and a lack of standardisation between assays (37). Moreover, response rates of 11 to $20 \%$ have been reported in patients with negative PD-L1 expression, highlighting its limited use as an independent biomarker for immunotherapy response (38).

The incorporation of additional predictive markers may improve patient selection and prevent avoidable toxicities and costs in individuals unlikely to benefit from treatment. EMT status has recently been identified as a potential candidate marker that can be implemented alongside PD-L1 to predict patient outcomes and response to therapy (39). Positive PD-L1 expression was significantly associated with the presence of EMT in the tumour tissues from 50 patients diagnosed with head and neck squamous cell carcinoma (19). Overall survival was significantly reduced in PD-L1 positive patients also demonstrating EMT features; these findings were confirmed in an independent validation cohort and two public databases. Similar findings have been observed in non-small-cell lung carcinoma (NSCLC) (40), thymic carcinoma (41), extrahepatic cholangiocarcinoma (42), oral squamous cell carcinoma (43), oesophageal squamous cell carcinoma (OSCC) (44) and hepatocellular carcinoma (45). We have also determined that PTC patients exhibiting a mesenchymal phenotype were more likely to co-express tumoural PD-L1 $(P=0.012)$. These findings were confirmed in the TCGA dataset analysis, in which a moderate positive linear relationship between EMT status and PD-L1 expression $(r=0.481171)$ as well as an IFN gene signature $(r=0.360384)$ was observed. In the subset of PTCs which experienced disease recurrence/progression $(n=40)$, a stronger correlation was identified between positive PD-L1 and EMT expression $(\mathrm{r}=0.623002)$; this was further strengthened when patients of all subtypes were included in the analysis $(n=49)(\mathrm{r}=0.656826)$. PD-L1, EMT status and CD8T cell expression were all not significantly associated with any clinicopathological characteristics; this may be a consequence of the relatively small cohort size, and the limited number of patients presenting with metastatic disease. EMT status remained the only significant predictor of DFS on multivariate analysis $(P=0.032)$; these findings were also reflected in the TCGA PTC patient cohort, in which a higher EMT and mesenchymal genes score were both significantly associated with a poorer DFS $(P=0.0027$ and $P=0.0085$, respectively).

The mechanisms by which EMT regulates components of the tumour immune microenvironment, including the PD-1/PD-L1 pathway, have recently been elucidated. A meta-analysis revealed that $P D-L 1$ gene expression was co-amplified along with the EMT associated genes MYC, SOX2, N-cadherin and SNAI1 in the endometrial and ovarian cancer datasets from TCGA (46). The gene promoter region of PD-L1 contains a binding site for ZEB1, a transcription factor which contributes to cancer stemness and tumourigenesis $(47,48)$. siRNA-mediated ZEB1 knockdown suppressed PD-L1 levels whilst promoting E-cadherin expression in OSCC (49). Cases expressing high PD-L1 at the invasive front also had significantly greater tumour invasion, EMT, and less CD8 lymphocyte infiltration. EMT-converted OSCC cell lines expressing high levels of PD-L1 at both protein and mRNA levels were capable of inducing T-cell apoptosis to a greater extent when compared to the original epithelial type tumour cells (44). In breast cancer cell lines, EMT-mediated PD-L1 upregulation occurred in parallel with the up- and downregulation of the stem-cell-related CD44 and CD24 surface markers, respectively; this was also accompanied by a morphological change from tightly arranged epitheliallike cells to widely distributed mesenchymal-like cells 
(22). A molecular relationship between EMT and CD8 T cells was demonstrated by Chen et al., in which ZEB1, an EMT activator and transcriptional repressor of miR-200 (a cell-autonomous suppressor of EMT and metastasis), was shown to relieve miR-200 repression of PD-L1 on tumour cells, resulting in CD8 T-cell immunosuppression and metastasis. These findings were further supported by a strong correlation between EMT score, levels of miR-200 and PD-L1 expression in numerous human lung cancer datasets. Preclinical models of melanoma, pancreatic and breast cancer have also demonstrated that the expression of certain transcription factors, such as Snail or Neu, can induce EMT and are associated with the activation of immunosuppressive cytokines and T-cell resistance. In our study, the prognostic capabilities of EMT were markedly enhanced when used in conjunction with PD-L1 and CD8 expression $(P<0.0001)$. Additional prospective studies exploring the interplay between CD8 T cells, EMT/ stromal elements and PD-L1 in larger patient cohorts will be needed to confirm these findings.

PD-1/PD-L1 oncogenic signalling has also been shown to play an important role in the regulation of EMT. Atezolizumab, an anti-PD-L1 checkpoint inhibitor, was shown to downregulate genes promoting cell migration, invasion and metastasis in the human triple negative breast cancer cell line MDA-MB-231 (50). In human glioblastoma multiform (GBM) cells, PD-L1 significantly altered cell growth, migration and invasion pathways by upregulating N-cadherin, vimentin, Slug (an E-cadherin transcriptional suppressor) and $\beta$-catenin (activates EMT via the PI3K/Akt/mTOR pathway), and downregulating E-cadherin gene expression (51). PD-L1 overexpression promoted GBM development and invasion in orthotopic GBM rat models. Following $48 \mathrm{~h}$ of IFN- $\gamma$ treatment, we also detected a significant increase in PD-L1 expression in all thyroid cancer cell lines examined. This rise in PD-L1 was accompanied by phenotypic changes indicative of a mesenchymal phenotype on imaging. This was confirmed on Western blot, where a significant downregulation in E-cadherin expression and upregulation of vimentin levels was observed. Similar findings were reported by Lo et al., in which IFNs enhanced RCC invasiveness by increasing both Slug and ZEB1 gene expression (52). IFN- $\gamma$ induced PD-L1 upregulation may therefore be involved in promoting EMT and may prove to be the missing link in the treatment of mesenchymal cancers. It is important to note that stromal cells have also been identified as a key source of EMT-related gene expression in colorectal, head and neck, and urothelial cancer (53, $54,55)$. In a cohort of patients with metastatic urothelial cancer treated with nivolumab, patients with T-cell infiltrated tumours and higher EMT/stroma-related gene expression experienced lower response rates and shorter progression-free and overall survival (53). Future research is required to delineate the distinct roles of PD-L1 and tumour-infiltrating stromal cells in activating EMT in thyroid cancer. Collectively, these studies illuminate the complex bidirectional regulation between EMT and PD-L1 signalling in cancer which ultimately leads to tumour immune escape and invasion.

Interestingly, an integrated analysis of the genomic and proteomic profiles from over 1000 tumours revealed that additional targetable immune checkpoints are present in cancers displaying an EMT phenotype, including T-cell immunoglobulin and mucin-domain containing-3 (TIM-3), OX40 and cytotoxic T-lymphocyteassociated protein 4 (CTLA-4) (56). EMT may therefore accelerate cancer growth and metastasis not only through the direct reprogramming of the PD-1/PD-L1 axis, but also via the modulation of several immune processes within the tumour microenvironment. This finding highlights the possibility of utilising EMT status as a supplementary tool for the selection of patients who may benefit from immune checkpoint inhibitors. Therapies targeting these additional immune checkpoints may impede tumour metastases and drug resistance mediated via EMT.

EMT status has also been shown to influence the degree of response to PD-1/PD-L1 targeted immunotherapies. Mammary tumour cells arising from epithelial carcinoma cell lines were found to express lower levels of PD-L1 and elevated MHC-I, CD8 T cells and M1 (anti-tumour) macrophages (57). In contrast, tumours from moremesenchymal carcinoma cell lines exhibited low levels of MHC-I and an elevated expression EMT markers, PD-L1, regulatory $\mathrm{T}$ cells, $\mathrm{M} 2$ (pro-tumour) macrophages and exhausted CD8 $\mathrm{T}$ cells within their stroma. The more mesenchymal carcinoma cells within a tumour were able to safeguard their more epithelial counterparts from immune attack, implicating the role of EMT in the regulation of the tumour microenvironment. Moreover, epithelial tumours were more susceptible to elimination by immunotherapy than corresponding mesenchymal tumours. Therefore, the implementation of EMT inhibitors as adjuvants to immune checkpoint immunotherapies may enhance responses in patients with mesenchymal tumours. In patients with advanced melanoma, EMT signatures and mesenchymal-related genes were associated with innate anti-PD-1 resistance (58). Additionally, patients with bladder tumours characterised by an epithelial phenotype had significantly higher response rates following

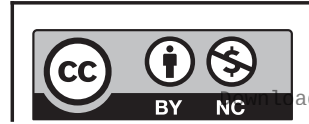


treatment with atezolizumab therapy compared to those harbouring a basal subtype (59). M7824, a novel first-inclass bifunctional anti-PD-L1 and TGF- $\beta$ fusion protein, was shown to revert TGF- $\beta$ mediated mesenchymalisation in NSCLC cells, as well as promote the activation of CD8 T and NK cells, reduce tumour growth and extend survival in animal models of colon and breast cancer. The concurrent blockade of the PD-L1 and TGF- $\beta$ pathways elicited superior antitumour activity compared to either monotherapy alone. These findings suggest that the efficacy of anti-PD-1/PD-L1 checkpoint inhibitors may be influenced by an individual's EMT status. Additional trials investigating the efficacy of combination strategies comprised of EMT targeted agents and immune checkpoint inhibitors will be needed to overcome patient resistance and improve survival outcomes.

There were a number of limitations present in our study, including its retrospective design, short median follow-up, and small sample size. Moreover, it is important to note that TMAs may not be representative of the whole patient specimen. Prospective, longitudinal studies with larger sample sizes will be needed to confirm the predictive value of PD-L1, CD8 T-cells and an EMT signature in thyroid cancer.

In conclusion, our results reveal the significant prognostic capabilities of PD-L1 expression, CD8 T cell status and EMT in PTC. Moreover, we provide a feasible mechanism for the promotion of EMT in thyroid cells that is mediated by PD-L1 expression in vitro. Patients exhibiting an EMT phenotype and positive PD-L1 expression may benefit from PD-1/PD-L1 targeted immunotherapy. Additional research exploring the molecular mechanisms underlying EMT regulation and its association with the PD-1/PD-L1 axis will enhance our understanding of thyroid carcinogenesis and provide alternative approaches for the treatment of patients with aggressive disease.

\section{Supplementary materials}

This is linked to the online version of the paper at https://doi.org/10.1530/ EC-20-0268.

\section{Declaration of interest}

The authors declare that there is no conflict of interest that could be perceived as prejudicing the impartiality of the research reported.

\section{Funding}

T L R is supported by a CINSW Future Research Leader fellowship and funding from the CONCERT translational cancer research centre. $\mathrm{A} J \mathrm{~J}$ supported by funding from Liverpool Hospital Medical Oncology and
Clinical Trials Unit. M J A is supported by a Western Sydney University PhD scholarship. U S holds a Fellowship from the Cancer Institute of New South Wales. Financial support was provided by the Cancer Council NSW (RG2012) to U S.

\section{References}

1 Morris LGT, Sikora AG, Tosteson TD \& Davies L. The increasing incidence of thyroid cancer: the influence of access to care. Thyroid 201323 885-891. (https://doi.org/10.1089/thy.2013.0045)

2 Sherman SI. Thyroid carcinoma. Lancet 2003361 501-511. (https:// doi.org/10.1016/s0140-6736(03)12488-9)

3 Pellegriti G, Frasca F, Regalbuto C, Squatrito S \& Vigneri R. Worldwide increasing incidence of thyroid cancer: update on epidemiology and risk factors. Journal of Cancer Epidemiology 2013 2013 965212. (https://doi.org/10.1155/2013/965212)

4 Leux C \& Guenel P. Risk factors of thyroid tumors: role of environmental and occupational exposures to chemical pollutants. Revue d'Epidemiologie et de Sante Publique 201058 359-367. (https:// doi.org/10.1016/j.respe.2010.05.005)

5 Kim H, Kim HI, Kim SW, Jung J, Jeon MJ, Kim WG, Kim TY, Kim HK, Kang HC, Han JM, et al. Prognosis of differentiated thyroid carcinoma with initial distant metastasis: a multicenter study in Korea. Endocrinology and Metabolism 201833 287-295. (https://doi. org/10.3803/EnM.2018.33.2.287)

6 Parameswaran R, Shulin Hu J, Min En N, Tan WB \& Yuan NK. Patterns of metastasis in follicular thyroid carcinoma and the difference between early and delayed presentation. Annals of the Royal College of Surgeons of England 201799 151-154. (https://doi. org/10.1308/rcsann.2016.0300)

7 Durante C, Haddy N, Baudin E, Leboulleux S, Hartl D, Travagli JP, Caillou B, Ricard M, Lumbroso JD, De Vathaire F, et al. Long-term outcome of 444 patients with distant metastases from papillary and follicular thyroid carcinoma: benefits and limits of radioiodine therapy. Journal of Clinical Endocrinology and Metabolism 200691 2892-2899. (https://doi.org/10.1210/jc.2005-2838)

8 Ross DS. Predicting outcome in patients with thyroid cancer. Journal of Clinical Endocrinology and Metabolism 201398 4673-4675. (https:// doi.org/10.1210/jc.2013-3989)

9 Francisco LM, Sage PT \& Sharpe AH. The PD-1 pathway in tolerance and autoimmunity. Immunological Reviews 2010236 219-242. (https://doi.org/10.1111/j.1600-065X.2010.00923.x)

10 Jiang X, Wang J, Deng X, Xiong F, Ge J, Xiang B, Wu X, Ma J, Zhou M, Li X, et al. Role of the tumor microenvironment in PD-L1/ PD-1-mediated tumor immune escape. Molecular Cancer 20191810. (https://doi.org/10.1186/s12943-018-0928-4)

11 Pyo JS, Kang G \& Kim JY. Prognostic role of PD-L1 in malignant solid tumors: a meta-analysis. International Journal of Biological Markers 201732 e68-e74. (https://doi.org/10.5301/jbm.5000225)

12 Aghajani M, Graham S, McCafferty C, Shaheed CA, Roberts T, DeSouza P, Yang T \& Niles N. Clinicopathologic and prognostic significance of programmed cell death ligand 1 expression in patients with non-medullary thyroid cancer: a systematic review and meta-analysis. Thyroid 201828 349-361. (https://doi.org/10.1089/ thy.2017.0441)

13 Shen X \& Zhao B. Efficacy of PD-1 or PD-L1 inhibitors and PD-L1 expression status in cancer: meta-analysis. BMJ 2018362 k3529. (https://doi.org/10.1136/bmj.k3529)

14 Mehnert JM, Varga A, Brose MS, Aggarwal RR, Lin CC, Prawira A, de Braud F, Tamura K, Doi T, Piha-Paul SA, et al. Safety and antitumor activity of the anti-PD-1 antibody pembrolizumab in patients with advanced, PD-L1-positive papillary or follicular thyroid cancer. BMC Cancer 201919 196. (https://doi.org/10.1186/s12885-019-5380-3)

15 Spencer KR, Wang J, Silk AW, Ganesan S, Kaufman HL \& Mehnert JM. Biomarkers for immunotherapy: current developments and 
challenges. American Society of Clinical Oncology Educational Book 2016 36 e493-e503.

16 Kalluri R \& Neilson EG. Epithelial-mesenchymal transition and its implications for fibrosis. Journal of Clinical Investigation 2003112 1776-1784. (https://doi.org/10.1172/JCI20530)

17 Satelli A \& Li S. Vimentin in cancer and its potential as a molecular target for cancer therapy. Cellular and Molecular Life Sciences 201168 3033-3046. (https://doi.org/10.1007/s00018-011-0735-1)

18 Shakib H, Rajabi S, Dehghan MH, Mashayekhi FJ, SafariAlighiarloo N \& Hedayati M. Epithelial-to-mesenchymal transition in thyroid cancer: a comprehensive review. Endocrine 201966 435-455. (https://doi.org/10.1007/s12020-019-02030-8)

19 Ock CY, Kim S, Keam B, Kim M, Kim TM, Kim JH, Jeon YK, Lee JS, Kwon SK, Hah JH, et al. PD-L1 expression is associated with epithelial-mesenchymal transition in head and neck squamous cell carcinoma. Oncotarget 20167 15901-15914. (https://doi. org/10.18632/oncotarget.7431)

20 Soundararajan R, Fradette JJ, Konen JM, Moulder S, Zhang X, Gibbons DL, Varadarajan N, Wistuba II, Tripathy D, Bernatchez C, et al. Targeting the interplay between epithelial-to-mesenchymal-tran sition and the immune system for effective immunotherapy. Cancers 201911 714. (https://doi.org/10.3390/cancers11050714)

21 Lou Y, Diao L, Cuentas ER, Denning WL, Chen L, Fan YH, Byers LA, Wang J, Papadimitrakopoulou VA, Behrens C, et al. Epithelialmesenchymal transition is associated with a distinct tumor microenvironment including elevation of inflammatory signals and multiple immune checkpoints in lung adenocarcinoma. Clinical Cancer Research 201622 3630-3642. (https://doi.org/10.1158/10780432.CCR-15-1434)

22 Alsuliman A, Colak D, Al-Harazi O, Fitwi H, Tulbah A, Al-Tweigeri T, Al-Alwan M \& Ghebeh H. Bidirectional crosstalk between PD-L1 expression and epithelial to mesenchymal transition: significance in claudin-low breast cancer cells. Molecular Cancer 201514149. (https://doi.org/10.1186/s12943-015-0421-2)

23 Maleki Vareki S. High and low mutational burden tumors versus immunologically hot and cold tumors and response to immune checkpoint inhibitors. Journal for ImmunoTherapy of Cancer 20186 157. (https://doi.org/10.1186/s40425-018-0479-7)

24 Caixeiro NJ, Morteza A, de Souza P \& Lee CS. The Centre for Oncology Education and Research Translation (CONCERT) biobank. Open Journal of Bioresources 20152 Art. e3. (https://doi.org/10.5334/ojb.ai)

25 Haugen BR, Alexander EK, Bible KC, Doherty GM, Mandel SJ, Nikiforov YE, Pacini F, Randolph GW, Sawka AM, Schlumberger M, et al. 2015 American Thyroid Association management guidelines for adult patients with thyroid nodules and differentiated thyroid cancer: the American Thyroid Association Guidelines Task Force on thyroid nodules and differentiated thyroid cancer. Thyroid 201626 1-133. (https://doi.org/10.1089/thy.2015.0020)

26 Kim S, Koh J, Kim MY, Kwon D, Go H, Kim YA, Jeon YK \& Chung DH. PD-L1 expression is associated with epithelialto-mesenchymal transition in adenocarcinoma of the lung. Human Pathology 201658 7-14. (https://doi.org/10.1016/j. humpath.2016.07.007)

27 Zhou F, Xu Y, Shi J, Lan X, Zou X, Wang L \& Huang Q. Expression profile of E-cadherin, estrogen receptors, and P53 in early-onset gastric cancers. Cancer Medicine 20165 3403-3411. (https://doi. org/10.1002/cam4.931)

28 Aghajani MJ, Yang T, McCafferty CE, Graham S, Wu X \& Niles N. Predictive relevance of programmed cell death protein 1 and tumor-infiltrating lymphocyte expression in papillary thyroid cancer. Surgery 2018163 130-136. (https://doi.org/10.1016/j. surg.2017.04.033)

29 Roberts TL, Ho U, Luff J, Lee CS, Apte SH, MacDonald KP, Raggat LJ, Pettit AR, Morrow CA, Waters MJ, et al. Smg1 haploinsufficiency predisposes to tumor formation and inflammation. PNAS 2013110 E285-E294. (https://doi.org/10.1073/pnas.1215696110)
30 Ayers M, Lunceford J, Nebozhyn M, Murphy E, Loboda A, Kaufman DR, Albright A, Cheng JD, Kang SP, Shankaran V, et al. IFN$\gamma$-related mRNA profile predicts clinical response to PD-1 blockade. Journal of Clinical Investigation 2017127 2930-2940. (https://doi. org/10.1172/JCI91190)

31 Gu Z, Eils R \& Schlesner M. Complex heatmaps reveal patterns and correlations in multidimensional genomic data. Bioinformatics 2016 32 2847-2849. (https://doi.org/10.1093/bioinformatics/btw313)

32 Topalian SL, Drake CG \& Pardoll DM. Targeting the PD-1/ B7-H1(PD-L1) pathway to activate anti-tumor immunity. Current Opinion in Immunology 201224 207-212. (https://doi.org/10.1016/j. coi.2011.12.009)

33 Chowdhury S, Veyhl J, Jessa F, Polyakova O, Alenzi A, MacMillan C, Ralhan R \& Walfish PG. Programmed death-ligand 1 overexpression is a prognostic marker for aggressive papillary thyroid cancer and its variants. Oncotarget 20167 32318-32328. (https://doi.org/10.18632/ oncotarget.8698)

34 Wu X, Gu Z, Chen Y, Chen B, Chen W, Weng L \& Liu X. Application of PD-1 blockade in cancer immunotherapy. Computational and Structural Biotechnology Journal 201917 661-674. (https://doi. org/10.1016/j.csbj.2019.03.006)

35 Sharma P, Hu-Lieskovan S, Wargo JA \& Ribas A. Primary, adaptive, and acquired resistance to cancer immunotherapy. Cell 2017168 707-723. (https://doi.org/10.1016/j.cell.2017.01.017)

36 Gibney GT, Weiner LM \& Atkins MB. Predictive biomarkers for checkpoint inhibitor-based immunotherapy. Lancet: Oncology 2016 17 e542-e551. (https://doi.org/10.1016/S1470-2045(16)30406-5)

37 Buttner R, Gosney JR, Skov BG, Adam J, Motoi N, Bloom KJ, Dietel M, Longshore JW, Lopez-Rios F, Penault-Llorca F, et al. Programmed death-ligand 1 immunohistochemistry testing: a review of analytical assays and clinical implementation in non-small-cell lung cancer. Journal of Clinical Oncology 201735 3867-3876. (https:// doi.org/10.1200/JCO.2017.74.7642)

38 Prelaj A, Tay R, Ferrara R, Chaput N, Besse B \& Califano R. Predictive biomarkers of response for immune checkpoint inhibitors in non-small-cell lung cancer. European Journal of Cancer 2019106 144-159.

39 Terry S, Savagner P, Ortiz-Cuaran S, Mahjoubi L, Saintigny P, Thiery JP \& Chouaib S. New insights into the role of EMT in tumor immune escape. Molecular Oncology 201711 824-846. (https://doi. org/10.1002/1878-0261.12093)

40 Asgarova A, Asgarov K, Godet Y, Peixoto P, Nadaradjane A, BoyerGuittaut M, Galaine J, Guenat D, Mougey V, Perrard J, et al. PD-L1 expression is regulated by both DNA methylation and NF-kB during EMT signaling in non-small cell lung carcinoma. Oncoimmunology 20187 e1423170. (https://doi.org/10.1080/2162402X.2017.1423170)

41 Funaki S, Shintani Y, Fukui E, Yamamoto Y, Kanzaki R, Ose N, Kanou T, Minami M, Mori E \& Okumura M. The prognostic impact of programmed cell death 1 and its ligand and the correlation with epithelial-mesenchymal transition in thymic carcinoma. Cancer Medicine 20198 216-226. (https://doi.org/10.1002/cam4.1943)

42 Ueno T, Tsuchikawa T, Hatanaka KC, Hatanaka Y, Mitsuhashi T, Nakanishi Y, Noji T, Nakamura T, Okamura K, Matsuno Y, et al. Prognostic impact of programmed cell death ligand 1 (PD-L1) expression and its association with epithelial-mesenchymal transition in extrahepatic cholangiocarcinoma. Oncotarget 20189 20034-20047. (https://doi.org/10.18632/oncotarget.25050)

43 Hirai M, Kitahara H, Kobayashi Y, Kato K, Bou-Gharios G, Nakamura H \& Kawashiri S. Regulation of PD-L1 expression in a high-grade invasive human oral squamous cell carcinoma microenvironment. International Journal of Oncology 201750 41-48. (https://doi.org/10.3892/ijo.2016.3785)

44 Thar Min AK, Okayama H, Saito M, Ashizawa M, Aoto K, Nakajima T, Saito K, Hayase S, Sakamoto W, Tada T, et al. Epithelial-mesenchymal transition-converted tumor cells can induce T-cell apoptosis through upregulation of programmed death ligand 1 expression

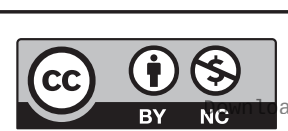

This work is licensed under a Creative Commons Attribution-NonCommercial 4.0 International License. ded from Bioscientifica.com at 04/26/2023 11:49:32AM 
in esophageal squamous cell carcinoma. Cancer Medicine 20187 3321-3330. (https://doi.org/10.1002/cam4.1564)

45 Shrestha R, Prithviraj P, Anaka M, Bridle KR, Crawford DHG, Dhungel B, Steel JC \& Jayachandran A. Monitoring immune checkpoint regulators as predictive biomarkers in hepatocellular carcinoma. Frontiers in Oncology 20188 269. (https://doi.org/10.3389/ fonc.2018.00269)

46 Dong P, Xiong Y, Yue J, Hanley SJB \& Watari H. Tumor-intrinsic PD-L1 signaling in cancer initiation, development and treatment: Beyond immune evasion. Frontiers in Oncology 20188 386. (https:// doi.org/10.3389/fonc.2018.00386)

47 Rosenbloom KR, Armstrong J, Barber GP, Casper J, Clawson H, Diekhans M, Dreszer TR, Fujita PA, Guruvadoo L, Haeussler M, et al. The UCSC Genome Browser database: 2015 update. Nucleic Acids Research 201543 D670-D681. (https://doi.org/10.1093/nar/gku1177)

48 Sánchez-Tilló E, Siles L, de Barrios O, Cuatrecasas M, Vaquero EC, Castells A \& Postigo A. Expanding roles of ZEB factors in tumorigenesis and tumor progression. American Journal of Cancer Research 20111 897-912.

49 Tsutsumi S, Saeki H, Nakashima Y, Ito S, Oki E, Morita M, Oda Y, Okano S \& Maehara Y. Programmed death-ligand 1 expression at tumor invasive front is associated with epithelial-mesenchymal transition and poor prognosis in esophageal squamous cell carcinoma. Cancer Science 2017108 1119-1127. (https://doi. $\operatorname{org} / 10.1111 /$ cas.13237)

50 Saleh R, Taha RZ, Sasidharan Nair V, Alajez NM \& Elkord E. PDL1 blockade by atezolizumab downregulates signaling pathways associated with tumor growth, metastasis, and hypoxia in human triple negative breast cancer. Cancers 201911 1050. (https://doi. org/10.3390/cancers11081050)

51 Qiu XY, Hu DX, Chen WQ, Chen RQ, Qian SR, Li CY, Li YJ, Xiong XX, Liu D, Pan F, et al. PD-L1 confers glioblastoma multiforme malignancy via Ras binding and Ras/Erk/EMT activation. Biochimica et Biophysica Acta (BBA): Molecular Basis of Disease 20181864 1754-1769.

52 Lo UG, Bao J, Cen J, Yeh HC, Luo J, Tan W \& Hsieh JT. Interferoninduced IFIT5 promotes epithelial-to-mesenchymal transition leading to renal cancer invasion. American Journal of Clinical and Experimental Urology 20197 31-45.
53 Wang L, Saci A, Szabo PM, Chasalow SD, Castillo-Martin M, Domingo-Domenech J, Siefker-Radtke A, Sharma P, Sfakianos JP, Gong Y, et al. EMT- and stroma-related gene expression and resistance to PD-1 blockade in urothelial cancer. Nature Communications 20189 3503. (https://doi.org/10.1038/s41467-01805992-x)

54 Isella C, Terrasi A, Bellomo SE, Petti C, Galatola G, Muratore A, Mellano A, Senetta R, Cassenti A, Sonetto C, et al. Stromal contribution to the colorectal cancer transcriptome. Nature Genetics 201547 312-319. (https://doi.org/10.1038/ng.3224)

55 Puram SV, Tirosh I, Parikh AS, Patel AP, Yizhak K, Gillespie S, Rodman C, Luo CL, Mroz EA, Emerick KS, et al. Single-cell transcriptomic analysis of primary and metastatic tumor ecosystems in head and neck. Cancer: Cell 2017171 1611.e24-1624. e24.

56 Mak MP, Tong P, Diao L, Cardnell RJ, Gibbons DL, William WN, Skoulidis F, Parra ER, Rodriguez-Canales J, Wistuba II, et al. A patientderived, pan-cancer EMT signature identifies global molecular alterations and immune target enrichment following epithelial-tomesenchymal transition. Clinical Cancer Research 201622 609-620. (https://doi.org/10.1158/1078-0432.CCR-15-0876)

57 Dongre A, Rashidian M, Reinhardt F, Bagnato A, Keckesova Z, Ploegh HL \& Weinberg RA. Epithelial-to-mesenchymal transition contributes to immunosuppression in breast carcinomas. Cancer Research 201777 3982-3989. (https://doi.org/10.1158/0008-5472. CAN-16-3292)

58 Hugo W, Zaretsky JM, Sun L, Song C, Moreno BH, Hu-Lieskovan S, Berent-Maoz B, Pang J, Chmielowski B, Cherry G, et al. Genomic and transcriptomic features of response to anti-PD-1 therapy in metastatic melanoma. Cell 2016165 35-44. (https://doi. org/10.1016/j.cell.2016.02.065)

59 Rosenberg JE, Hoffman-Censits J, Powles T, van der Heijden MS, Balar AV, Necchi A, Dawson N, O'Donnell PH, Balmanoukian A, Loriot $\mathrm{Y}$, et al. Atezolizumab in patients with locally advanced and metastatic urothelial carcinoma who have progressed following treatment with platinum-based chemotherapy: a single-arm, multicentre, phase 2 trial. Lancet 2016387 1909-1920. (https://doi. org/10.1016/S0140-6736(16)00561-4)

Received in final form 31 August 2020

Accepted 28 September 2020

Accepted Manuscript published online 29 September 2020
This work is licensed under a Creative Commons Attribution-NonCommercial 4.0 International License. ded from Bioscientifica.com at 04/26/2023 11:49:32AM 